\title{
EVOLUÇÃO ESTRUTURAL DA FAIXA SETENTRIONAL DO GRUPO SÃO JOÃO DEL REI, MINAS GERAIS
}

\author{
CARLOS MAURÍCIO NOCE*
}

\begin{abstract}
STRUCTURAL EVOLUTION OF THE NORTHERN PART OF SÃO JOÃO DEL REI GROUP, MINAS GERAIS. Three deformation phases have been distinguished in the São João del Rei Group. $D_{1}$ and $\mathrm{D}_{2}$ are related possibly to one progressive deformation with an important simple shear component. The most representative $D_{1}$ structure is a well developed slaty cleavage. During $D_{2}$ a crenulation cleavage and important meso and macrom folds developed. $D_{2}$ folds plus stratigraphic wedging and repetition are responsible for the general map pattern of the Såo Joäo del Rei Group. The last deformation phase; $D_{3}$, was weaker than the former ones. $D_{3}$ structures are open folds, crenulations and a less common spaced cleavage. The peak of metamorphic conditions was attained during $D_{2}$ Medium greenschist facies metamorphism (biotite zone) is recorded all over the area, except for the extreme southeast, where almandine garnet has been found.
\end{abstract}

RESUMO Três fases de deformação têm sido reconhecidas no Grupo São João Del Rei: $D_{1}$ e $D_{2}$ săo possivelmente relacionadas a uma deformação progressiva, com um importante componente de crisalhamento simples. A mais representativa estrutura $\mathrm{D}_{1}$ \& configurada por uma clivagem ardosiana bem desenvolvida; durante $D_{2}$, uma clivagem de crenulação e dobras importantes de escalas meso e macroscópicas desenvolveram-se. As dobras $D_{2}$ o empilhamento estratigráfico e as repetiçöes são

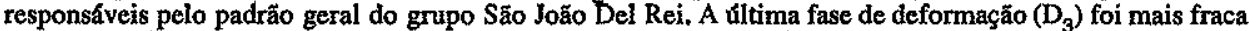
que as anteriores e originou dobras abertas, crenulaçóes e uma clivagem espaçada pouco comum. $O$ pico metamórfico deu-se durante a fase $\mathrm{D}_{2}$, atingindo o fácies xistos-verdes médio (zona da biotita) na maior parte da área, com exceção do extremo sudeste, onde granada almandina pode ser encontrada.

INTRODUÇÃo O Grupo São João del Rei constitui uma seqüência essencialmente metassedimentar, posicionada ao longo da borda meridional do Cráton do São Francisco, cobrindo uma área extensa na região sul do Estado de Minas Gerais.

O presente trabalho aborda a faixa setentrional desta unidade, balizada pelas cidades de Barbacena, Carandaí e São Joảo del Rei (Fíg. 1). Nesta área, a sequiência pode ser dividida em três formaçöes, adotando-se, com modificaçöes, a terminologia proposta por Ebert $(1956,1968)$. A Formaçăo Tiradentes, basal, tem ocorrência restrita às cercanias das cidades de São João del Rei e Tiradentes, e e composta predominantemente por quartzitos, somados a metaconglomerados e rochas filíticas. A Formaçăo Prados engloba filitos de aspecto listrado, localmente grafitosos (em especial na base da formaçáo), calcifilitos e lentes de metacalcário que atingem ate dezenas de metros de espessura. Essas rochas carbonáticas constituem o Membro Barroso. A unidade de topo $\varepsilon$ designada Formaçáo Rio Elvas, apresentando filitos cinzentos e quartzitos micáceos intercalados, e uma espessa seqüência de quartzo-biotita xistos, frequientemente felđspáticos. As formaçóes Prados e Rio Elvas mostram contatos gradacionais e transiçôes laterais.

No Grupo Săo Joâo del Rei são freqüentes as feiçōes indicativas de deformaçóes multiplas, como dobras redobradas, clivagens e lineaçőes dobradas, transposiçáo de clivagem etc. A utilização desses critérios de superimposição permitiu distinguir três fases de deformação (Trouw et al. 1983), representando conjuntos de estruturas formadas consecutivamente ou em seqüência progressiva, não implicando, necessariamente, eventos deformativos distintos.

TRABALHOS ANTERIORES Os trabalhos de Ebert $(1957,1958,1984)$ são os primeiros a tratar, com maior detalhe, os aspectos da geologia estrutural do Grupo São Joăo del Rei na região em causa. Este assunto foi retomado por Trouw (1983), Trouw et al. (1983) e mais recentemente por Valeriano (1983), (1985, 1986) (Fig. 2) e Noce (1987a, 1987b).

\section{GEOLOGIA ESTRUTURAL Fases de deformação} FASE $D_{1} \quad$ Em outras áreas de ocorrência do Grupo São João del Rei foram descritas estruturas $\mathrm{D}_{1} \mathrm{em}$ grande escala, como dobras e cavalgamentos (Trouw op. cit., Ribeiro 1983). $\mathrm{Na}$ área estudada, as dobras $\mathrm{D}_{1}$ são raras o observadas apenas em escala de afloramento e amostra de mâo. Encontram-se, por via de regra, redobradas por $\mathrm{D}_{2}$ em um padräo "em laço" (Fig. 3A), A principal estrutura relacionada a $D_{1} \in$ uma clivagem do tipo ardosiano, $S_{1}$, 'bem desenvolvida e de distribuição ampla (exceto nos quartzitos bastante puros da Formaçẫo Tiradentes).

A clivagem $S_{1}$ pode ser reconhecida em filmes micáceos freqüentes tanto nas rochas quartzíticas da Formaçảo Rio Elvas, como nos metacalcários. Esses filmes definem uma superfície de clivagem dobrada nas charneiras de dobras $D_{2}$, evidenciando seu caráter pre- $\mathrm{D}_{2}$ (Fig. 3B). Nos xistos e filitos ocorre, geralmente, forte crenulaçăo e transposição devido à fase subseqüente, de forma que $S_{1}$ tende a ser preservada apenas nos microlítons que separam as superfícies $S_{2}$. Seu 

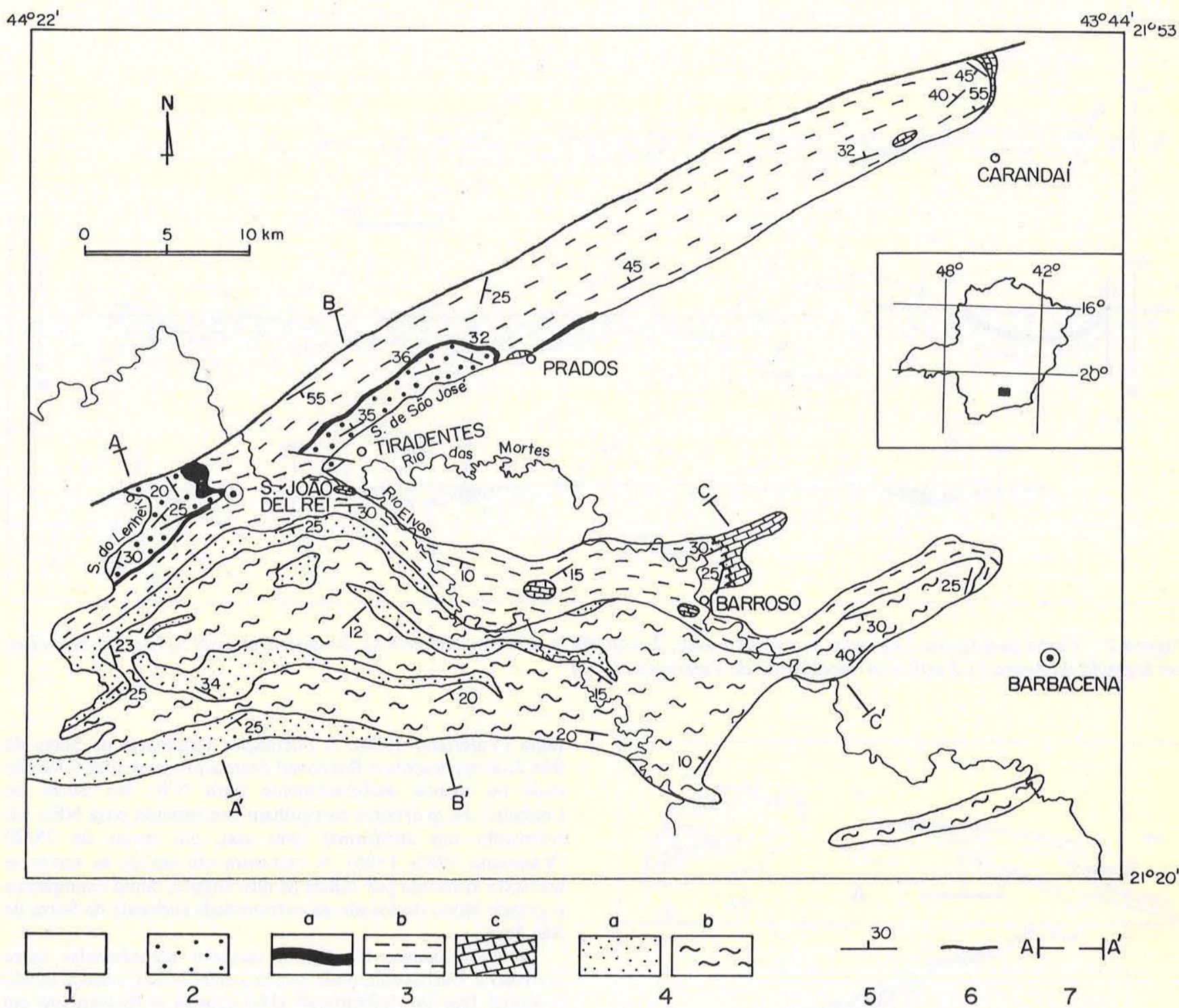

Figura 1 - Mapa geológico da faixa setentrional do Grupo São João del Rei (segundo Ebert 1956, 1984, Valeriano 1985, Noce 1987a). Legenda: 1. embassamento; 2, 3 e 4. Grupo São João del Rei (base para o topo); 2. Formação Tiradentes (quartzitos, metaconglomerados, filitos); 3. Formação Prados (3a. filitos pretos, grafitosos; 3b. filitos listrados; 3c. metacalcários); 4. Formação Rio Elvas (4a. filitos cinzentos e quartzitos micáceos; 4b. quartzo-biotita xistos). Símbolos: 5. atitude de acamamento; 6. falha; 7. linha de perfil (ver figura 2)

aspecto morfológico mais comum é representado pela marcante orientação de finas palhetas de mica branca. Nos quartzo-biotita xistos é possível observar um bandamento diferenciado paralelo a $S_{1}$, dado pela alternância milimétrica de bandas enriquecidas em quartzo e mica. Este bandamento aparenta uma origem secundária do tipo que deriva dos processos de pressure solution associados ao desenvolvimento de uma clivagem de crenulação (Nicholson 1966, Gray \& Durney 1979).

Um aspecto importante a respeito da clivagem $\mathrm{S}_{1}$ é sua tendência ao paralelismo com planos de estratificação $\left(\mathrm{S}_{0}\right)$, verificado onde a identificação deste.último se faz possível. Considerando a ausência de evidências de um dobramento isoclinal $\mathrm{D}_{1}$ regional, ao qual pudesse ser atribuído esse paralelismo, Noce (1987b) discute a possibilidade de a clivagem $\mathrm{S}_{1}$ ter evoluído, parcialmente, a partir do crescimento metamórfico de minerais micáceos segundo uma anisotropia planar primária, sub-horizontal, originada quando do soterramento dos sedimentos (a gênese deste tipo de estrutura É analisada por Maltman 1981). E provável que a deformação $\mathrm{D}_{1}$ tenha se caracterizado por intenso cisalhamento de baixo ângulo, no qual o dobramento é restrito ou mesmo não se desenvolve. Este modelo poderia gerar uma clivagem $\mathrm{S}_{1}$ exclusivamente tectônica ou, em parte, preservar e reforçar uma anisotropia primária. Na segunda hipótese, essa estrutura planar inicial poderia também sofrer, localmente, crenulação e transposição, gerando o bandamento diferenciado segundo $\mathrm{S}_{1}$.

FASE DE DEFORMAÇÃO $D_{2} \quad \mathrm{D}_{2}$ foi a principal fase de deformação que atingiu o Grupo São João del Rei, gerando os dobramentos mais importantes, uma clivagem plano-axial $\mathrm{S}_{2} \mathrm{e}$ mais de um tipo de lineação.

A fase $D_{2}$ forma amplas estruturas sinformais e antiformais, abertas e com superfície axial de alto ângulo a 


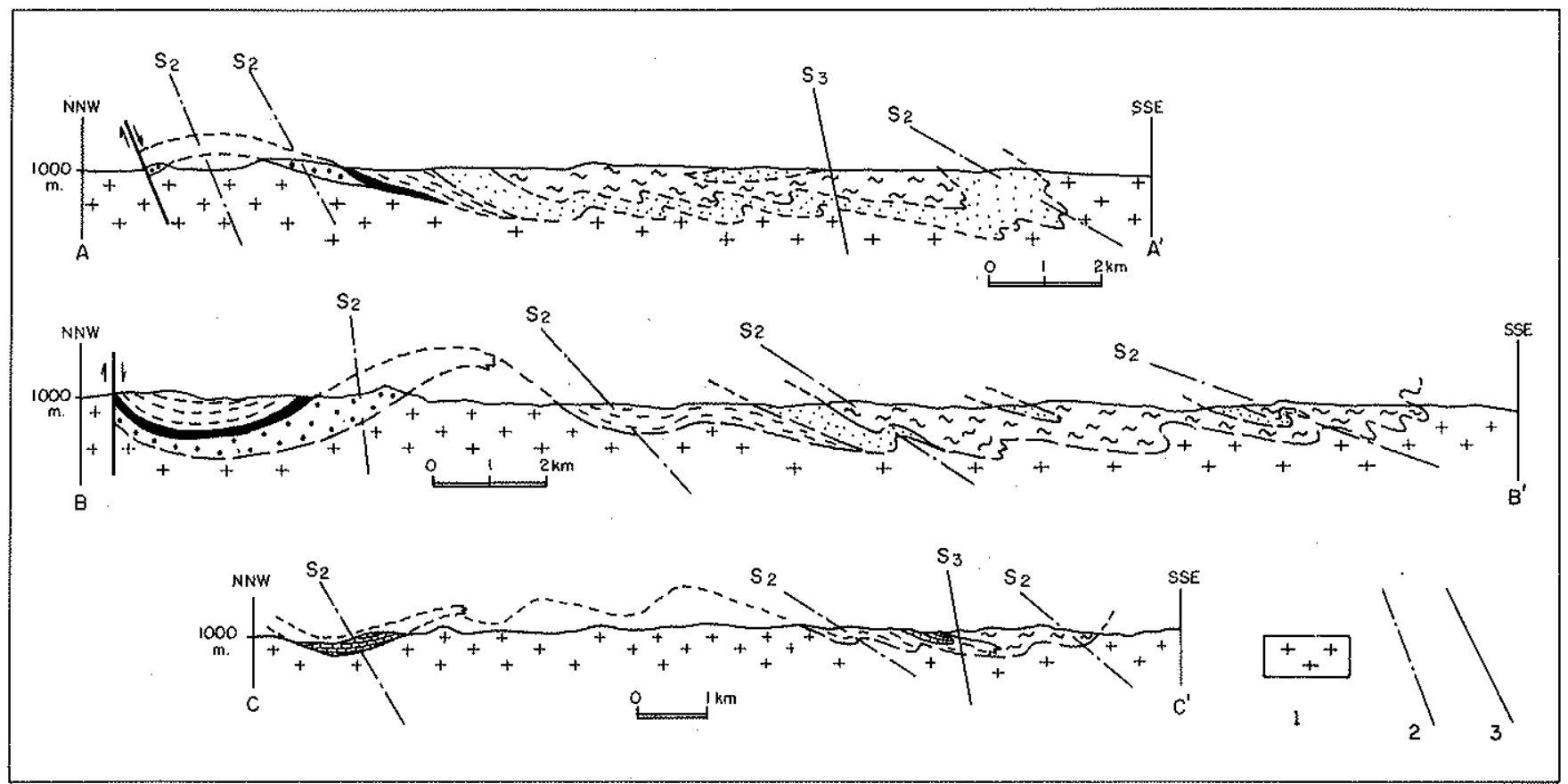

Figura 2 - Perfis geologicos. Legenda: 1. embasamento; 2. superficie axial ou clivagem $S_{2} ; 3$. superficie axial $S_{3}$ (demais simbolos, ver legenda da figura 1). Perfil A-A' modificado de Valeriano (1986)

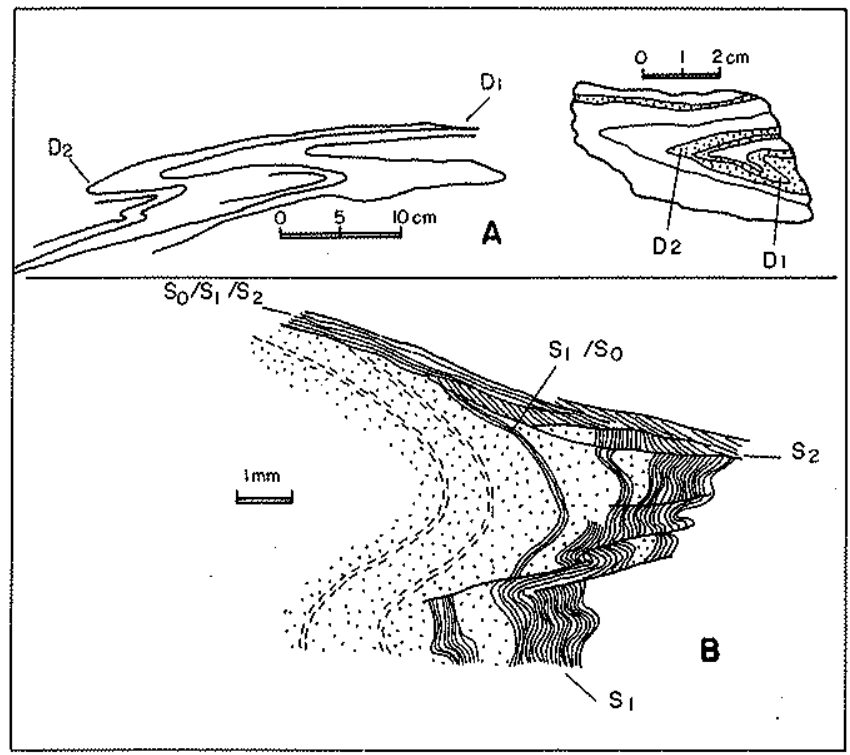

Figura 3 - Estruturas da fase $D_{1}$ : A. dobras $D_{1}$ redobradas por $D_{2} ;$ B. relações entre $S_{1}$ e $S_{2}$ em charneira de microdobra $D_{2}$ (a rocha é um quartzito micáceo)

norte e, progressivamente, mais deitadas a sul. A faixa que se inicia em Carandaí constitui um sinformal aberto, incluindo sinformais e antiformais menores, com eixo em torno de NE-SW. A superfficie axial das dobras (a clivagem $S_{2}$ ) forma um leque com mergulhos superiores a $45^{\circ}$ para NW e SE. Essa estrutura é limitada a norte por um falhamento de alto angulo, provavelmente associado a $\mathrm{D}_{2}$, devido ao fato de, na Serra do Lenheiro, a clivagem $S_{2}$ nos quartzitos se torna progressivamente mais bem desenvolvida nas proximidades da falha (Valeriano 1986). A Formação Tiradentes na Serra de São José representa o flanco sul deste sinformal, mergulhando mais ou menos uniformemente para NW. Na Serra do Lenheiro, os quartzitos mergulham suavemente para NE e SE formando um antiformal com eixo em torno de 75/20 (Valeriano 1985, 1986). A estrutura em ambas as serras se encontra truncada por falhas de alto ângulo, como exemplifica o grande bloco deslocado na extremidade sudoeste da Serra de Săo José.

Dobras maiores $D_{2}$ foram também reconhecidas entre Barroso e Barbacena, onde um provável basculamento ligado à última fase de deformação $\left(\mathrm{D}_{3}\right)$ causou o fechamento em mapa das dobras em direção leste. A seqüência se divide em duas faixas separadas pelo embasamento, que correpondem a estruturas sinformais. A faixa menor, a nordeste de Barroso, 6 constitúda por calcários e filitos da Formaçáo Prados. O mergulho geral das camadas $\varepsilon$ baixo $e$ a estrutura foi interpretada como uma calha sinformal bastante rasa, possivelmente a raiz de uma estrutura maior quase totalmente erodida. $O$ segundo sinformal tem extensão maior, fechando nas proximidades de Barbacena.

O contato sul do Grupo São Joâo del Rei foi interpretado como um empurrão por Ebert (1956), colocando os gnaisses do embasamento sobre os biotita-quartzo xistos da Formação Rio Elvas. Não foram observadas evidências concretas deste empurrão e, possivelmente, o que ocorre neste contato $e$ uma dobra de flanco invertido, na qual, em função do nível de erosão, os xistos podem aparecer em posição normal ou inversa.

O estilo das dobras $D_{2}$ em escala mesoscópica (Fig. 4) varia tanto em função da litologia como da posição dentro do cinturăo. Na porçăo norte, podem ser observadas dobras abertas com superfície axial ingreme. A sul, as dobras são fortemente assimétricas a fechadas e mesmo isoclinais. Apresentam adelgaçamento nos flancos e espessamento apical, aproximando-se do tipo similar de dobramento. A superfície axial, por via de regra, mergulha com valores inferiores a $30^{\circ}$. Os melhores exemplos dessas dobras são encontrados nos 
quartzitos micáceos e metacalcários (Fig. 4), posto que, nas rochas xistosas, a transposição mais intensa leva, freqüentemente, à obliteração das charneiras.

N

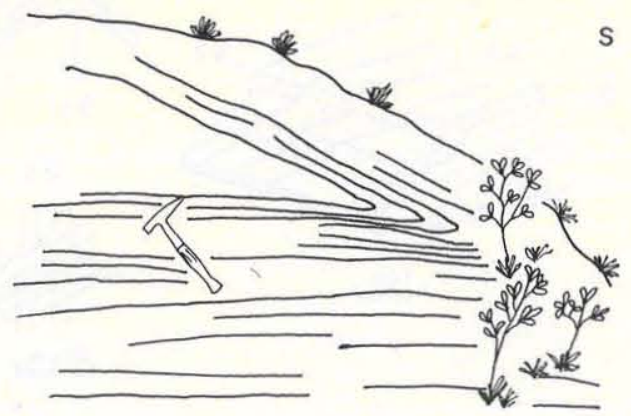

A

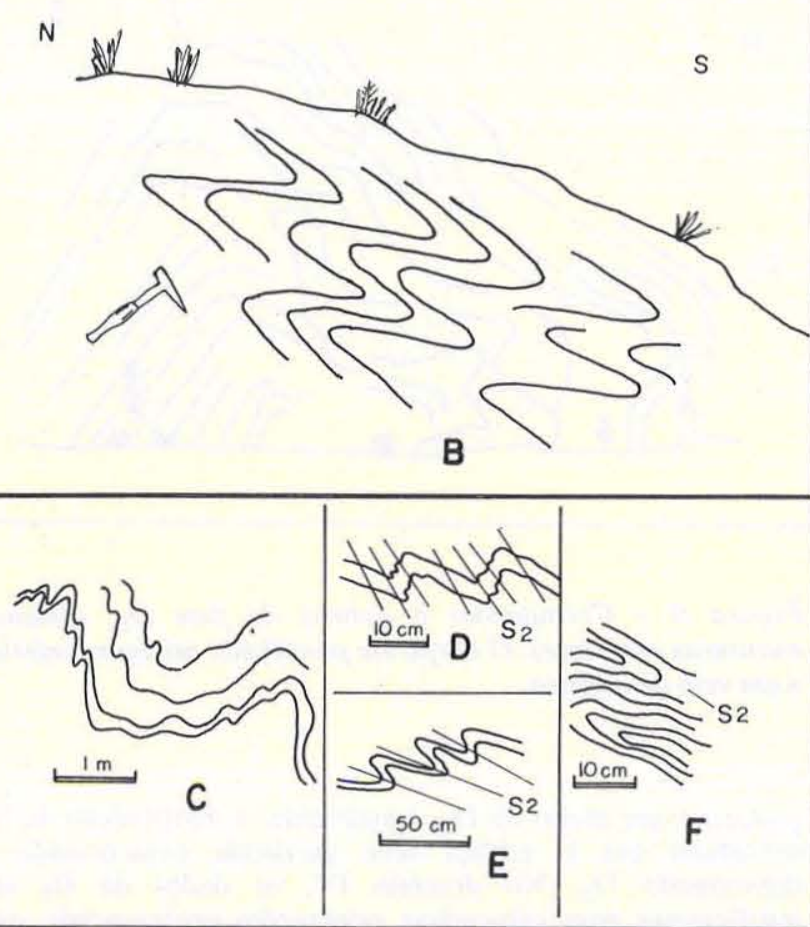

Figura 4 - Dobras $\mathrm{D}_{2}$ exibindo estilos variados: A. dobra deitada em quartzito micáceo da Formação Rio Elvas (afloramento no Córrego do Inhambu, a sul de Tiradentes); $\mathbf{B}$. dobramento apertado e simétrico em metacalcário (pedreira na localidade de Ribeiräo do Elvas); C. dobra aberta com superficie axial íngreme em metacalcário (pedreira a norte de Carandaí); D. e E. dobras assimétricas em metacalcário (pedreiras a nordeste e leste de Barroso); F. dobra apertada em xisto (sul de Tiradentes)

Associam-se à fase $D_{2}$ lineações do tipo interseção e crenulação. Na parte mais a sul do cinturão, em especial nos xistos da Formação Rio Elvas, é comum a presença de uma lineação definida pela orientação de palhetas de biotita, cuja direção coincide aproximadamente com a dos eixos de dobra $\mathrm{D}_{2}$ na área (vide item sobre "Análise Estatística"). As possíveis implicaçōes cinemáticas dessa estrutura são analisadas por Noce (1987 a), quando se considera a possibilidade de a lineação mineral representar uma lineação de estiramento aparente, no sentido definido por Sanderson (1974).
A superfície $\mathrm{S}_{2}$ é uma clivagem de crenulação (Fig. 5A), de desenvolvimento irregular, sendo possível a observação dos vários estágios evolutivos de uma clivagem desse tipo (Bell \& Rubenach 1983). Nos xistos, localmente, constata-se apenas o microdobramento da superfície anterior $\mathrm{S}_{1}$, sem o desenvolvimento de uma nova superfície de clivagem. Mais comumente, $\mathrm{S}_{2}$ é uma superfície bem definida, separando microlítons, onde $S_{1}$ está preservada. Ao longo de $S_{2}$ ocorre tanto o enriquecimento em mica devido à dissolução do quartzo, como o crescimento orientado de novas micas (biotita). Freqüentemente, a clivagem é reforçada por filmes de opacos, resíduos de dissolução. Em um estágio evolutivo mais avançado, os restos da superfície anterior tendem a ser "apagados", restando uma clivagem definida por forte orientação de minerais micáceos e paralela a um bandamento diferenciado, tipificado pela alternância de domínios quartzosos e micáceos.

Este bandamento diferenciado (metamorphic layering, Williams 1972; differentiated layering, Hobbs et al. 1976) é uma feição marcante nos quartzo-biotita xistos da Formação Rio Elvas. A espessura das bandas varia em média entre 0,2 a $1,5 \mathrm{~mm}$, são contínuas ou mais raro lenticulares ou anastomosadas. A passagem das bandas micáceas para as quartzosas é, com freqüência, bem definida. Nestas últimas, o quartzo mostra texturas poligonizada e a direção de clivagem é dada por filmes de mica descontínuos ou pela orientação de palhetas individuais (Fig. 5B).

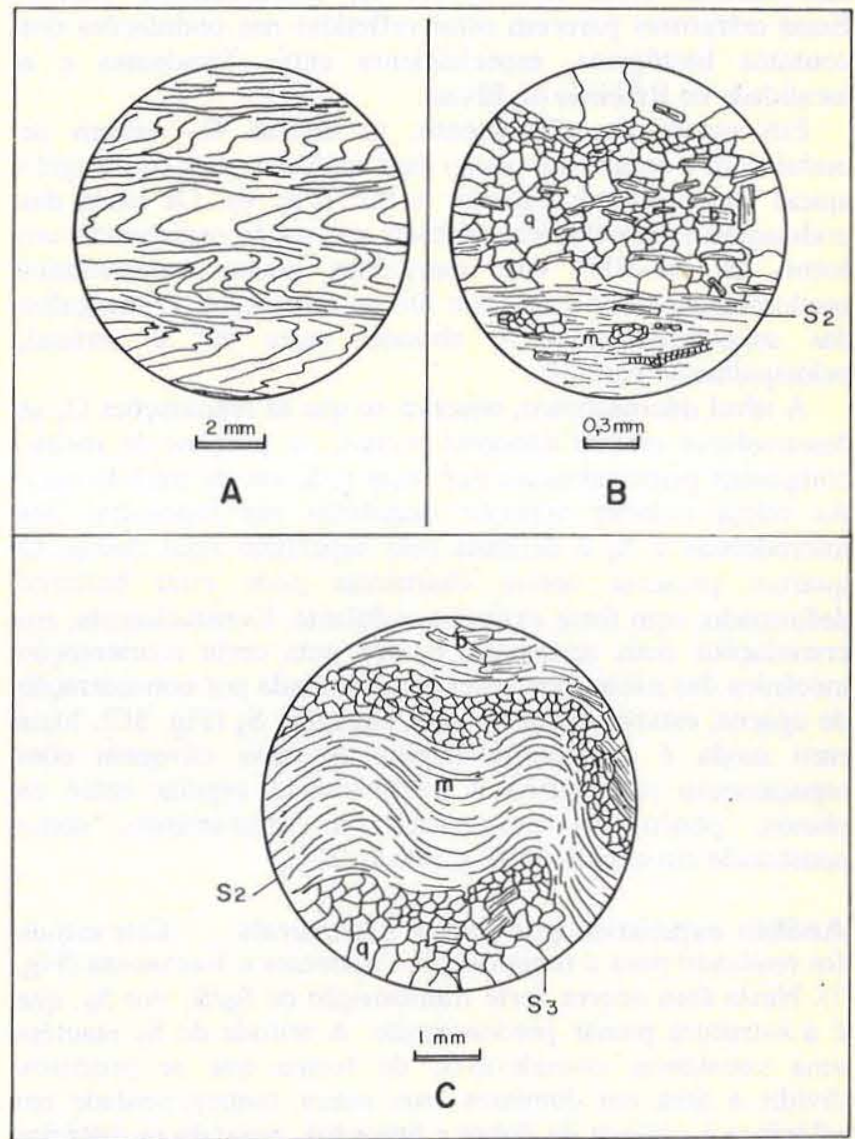

Figura 5 - Aspectos das superfícies $\mathrm{S}_{2}$ e $\mathrm{S}_{3}$ em lâmina delgada (q: quartzo; b: biotita; $m$ : mica branca): A. transposição parcial da superfície $S_{1}$ por $S_{2}$; B. bandamento diferenciado paralelo $a S_{2}$ (quartzo-biotita xisto); C. crenulação $D_{3}$. A microdobra mais apertada (à direita) mostra o desenvolvimento incipiente de uma superfície de clivagem $S_{3}$ 
O tipo litologico e um fator essencial na determinação da morfologia da clivagem. Nos quartzitos bastante puros da Formaçâo Tiradentes $S_{2}$ e geralmente uma clivagem espaçada ou de fratura. De forma semelhante, em metacalcários livres de minerais silicáticos, a clivagem tem desenvolvimento incipiente, aparecendo como superfícies espaçadas. Em lâmina constata-se que o carbonato ocorre basicamente em grãos eqüidimensionais e as superfícies de clivagem são definidas pelo alinhamento de interfaces retilíneas entre grãos, correspondendo provavelmente a planos de dissolução. Conforme assinalam Marshak \& Engelder (1985), o desenvolvimento de clivagem em rochas carbonáticas 6 uma função direta do teor em impurezas. Nos calcários impuros, os grãos de carbonato se apresentam alongados ou tabulares, o que associado á orientaçâo de minerais micáceos, origina uma clivagem penetrativa.

FASE DE DEFORMAÇÃO $D_{3} \quad$ A última fase de deformação foi de intensidade consideravelmente menor que as anteriores, sua principal manifestação sendo uma crenulação desenvolvida em especial nas rochas filíticas (Fig. 6). Localmente, as estruturas pré- $D_{3}$ se encontram muito perturbadas, mas, por via de regra, $\mathrm{D}_{3}$ é representada pela crenulação e por ondulações suaves, quando não está ausente ao menos em escala mesoscópica. $\mathrm{O}^{\circ}$ desenvolvimento irregular é uma característica básica desta última fase.

A distribuição de $S_{2}$ e $L_{2}$, nos estereogramas, não evidenciam com clareza os efeitos de $D_{3}$, indicando que as macrodobras desta fase devem ser extremamente suaves. Essas estruturas parecem estar refletidas nas ondulações dos contatos litológicos, especialmente entre Tiradentes e a localidade de Ribeirão do Elvas.

Em escala de afloramento, as dobras $D_{3}$ variam de ondulaçóes a dobras um pouco mais fechadas, mas com ângulo apical quase sempre superior a $90^{\circ}$ (Fig. 6). Os eixos das ondulaçōes e crenulaçōes mostram orientação preferencial em torno de NE-SW, com mergulhos pouco pronunciados predominantemente para este filtimo quadrante. $\mathrm{O}$ mergulho das superfícies axiais é elevado, entre $60^{\circ}$ e vertical, principalmente para SE.

A nf́lel microscópico, observa-se que as crenulaçōes $D_{3}$ se desenvolvem melhor naquelas rochas, ou porçöes da rocha, compostas principalmente por finas palhetas de mica branca. As micas exibem extinção ondulante nas chameiras das microdobras e $\mathrm{S}_{3}$ é definida pela superfície axial destas. $\mathrm{O}$ quartzo presente nessas charneiras pode estar bastante deformado, com forte extinção ondulante. Eventualmente, em crenulações mais apertadas, ocorre uma certa reorientaçāo mecânica das micas, por vezes acompanhada por concentração de opacos, estabelecendo-se uma clivagem $S_{3}$ (Fig. 5C). Mais raro ainda é o desenvolvimento de uma clivagem com espaçamento milimétrico e relativamente regular entre os planos, penetrativa em escala de afloramento, como constatado em exposiçăo de metacalcários.

Análise estatística dos dados estruturais Este estudo foi realizado para a regiảo entre Tiradentes e Barbacena (Fig. 7). Nesta área ocorre forte transposição de $S_{0} / S_{1}$ por $S_{2}$, que é a estrutura planar predominante. $A$ atitude de $S_{2}$ mantém uma constância considerável, de forma que se procurou dividir a área em domínios com maior homogeneidade em relação a $\mathbf{L}_{2}$ (eixos de dobra e lineação), segundo os critérios de Turner \& Weiss (1963). Existe uma evidente tendência de rotação de $\mathrm{L}_{2}$ no sentido anti-horário do domínio I para o III (os máximos são, respectivamente, 116/14, 100/07 e 68/12). No domínio IV (Carandaí), o giro é ainda maior. O caimento dos eixos é, principalmente, para os quadrantes SE (I e II) e NE (III), mas reversöes de quadrantes são observadas, em especial nos domínios III e IV, onde os eixos das macrodobras mergulham para SW. Tais mudanças no sentido đo mergulho

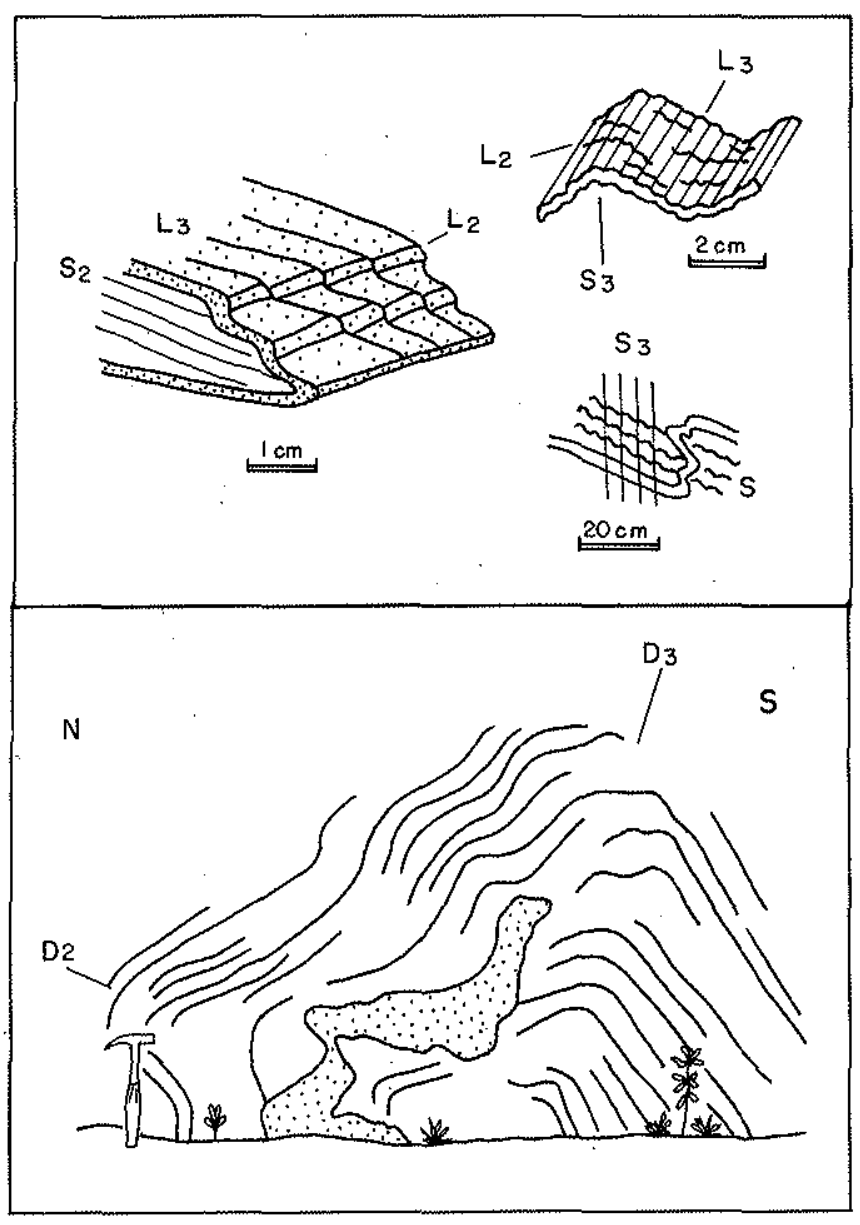

Figura 6 - Crenulaçöes $e$ dobras da fase $D_{3}$, afetando estruturas anteriores. $O$ corpo em pontilhado na figura inferior é um veio de quartzo

poderiam ser efeito de $D_{3}$. Igualmente, a distribuição de $S_{2}$, sobretudo em I, esboça uma guirlanda evidenciando o dobramento $D_{3}$. No domínio IV, os dados de $D_{3}$ são insuficientes para caracerizar orientaçōes preferenciais, mas fica sugerida uma certa co-axilidade $\mathrm{D}_{2} / \mathrm{D}_{3}$ (comparar os estereogramas sinopticos de $S_{3}$ e $L_{3}$ com $S_{2}$ e $L_{2}$ em IV). As dobras são abertas e $S_{2}$ é íngreme e com distribuição em leque, contrastanto com os demais domínios.

Os estereogramas de $\mathrm{L}_{2}$ apresentam uma distribuição em um grande círculo aproximadamente coincidente com a orientação preferencial de $S_{2}$. Este comportamento $\hat{\epsilon}$ constatado mesmo em um conjunto de medidas tomado a nível de afloramento. Caso a dispersão de $\mathrm{L}_{2}$ fosse umefeito de $\mathrm{D}_{3}$, deveria esperar-se uma distribuição em pequeno círculo, considerando que o dobramento $D_{3}$ foi provavelmente do tipo flexural. Deste modo, a variaçăo na atitude dos eixos de dobras $\mathrm{D}_{2}$ deve refletir $\mathrm{o}$ caráter acilíndrico e/ou não-homogêneo do dobramento. Conforme assinalam Turner \& Weiss (1963), em um dobramento acilíndrico de superfície axial planar, os eixos de cada segmento de dobra ou dobra menor aproximadamente cilíndrica na escala de observação, quando lançados em estereograma, irāo definir um grande círculo coindidente com a superfície axial do dobramento. Esta É a situação revelada nos estereogramas de $\mathrm{L}_{2}$. No estereograma sinóptico de $\mathrm{L}_{2}$ da figura 8 , foi traçada uma linha cheia que representa o grande círculo (plano) de melhor ajuste das medidas de $\mathrm{L}_{2}$, passando por seu máximo. $\mathrm{Na}$ 


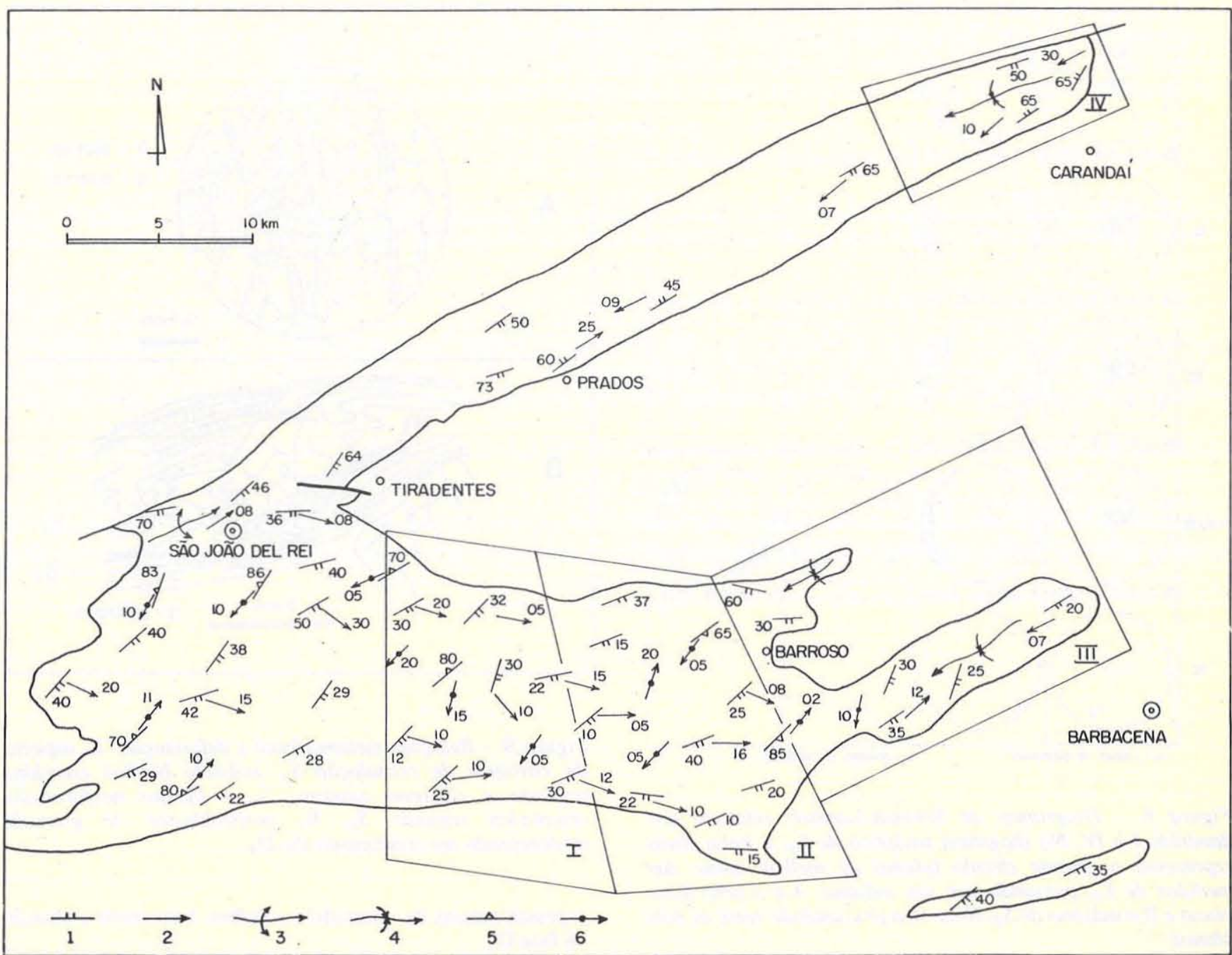

Figura 7 - Elementos estruturais das fases $D_{2}$ e $D_{3}$.e localização dos domínios com análise estatística. Símbolos: 1. $S_{2} ; 2$. $L_{2} ; 3$. antiformal $D_{2} ;$ 4. sinformal $D_{2} ;$ 5. $S_{3} ; 6 . L_{3}$ (Obs.: dados da regiäo de São João del Rei extraídos de Valeriano 1985)

figura, A é o pólo deste plano e $\mathrm{B}$, o máximo de $\mathrm{S}_{2}$, e são quase coincidentes. Esta dispersão dos eixos dentro da superfície axial $\mathrm{S}_{2}$, responsável pelo caráter acilíndrico do dobramento, poderia ser atribuido a um giro dos eixos de dobra durante a deformação. Quanto à dispersão de $\mathrm{L}_{3}$, esta reflete $o$ fato de $D_{3}$ afetar superfícies com orientações variadas enquanto a dispersâo de $\mathrm{S}_{3}$ sugere um leque.

EVOLUÇÃo ESTRUTURAL E METAMÓRFICA As fases $D_{1}$ e $D_{2}$ foram provavelmente geradas em um único evento de deformação progressiva, conforme afirma Trouw et al. (1983):“(...) é possível que as estruturas $\mathrm{D}_{1}$ e $\mathrm{D}_{2}$ reflitam diferentes respostas do conjunto rochoso, conforme este conjunto foi gradualmente aquecido, e que o campo de esforços era essencialmente o mesmo". Admitindo-se uma deformação $D_{1} / D_{2}$ progressiva nāo-coaxial, as estruturas $D_{1}$ (clivagem, bandamento metamórfico, dobras) formadas no estágio inicial vão sendo deformadas em um processo contínuo, ainda que não-homogêneo e dificilmente síncrono em todo o cinturẫo. As estruturas $\mathrm{D}_{2}$ representariam o estágio final do evento deformativo, coincidente com o pico do metamorfismo.

O Grupo São João del Rei, na área estudada, encontra-se quase totalmente na fácies xistos verde média do metamorfismo, zona da biotita. Apenas na extremidade sudeste da área aparece a granada almandina denunciando uma certa elevação nas condições metamórficas. A evolução do metamorfismo é reconstituída pelos estudos de microtectônica. Em charneiras de microdobras $D_{2}$ observam-se biotitas segundo $S_{1}$, crenuladas, e o crescimento de novas biotitas perfeitamente orientadas segundo $S_{2}$ (Fig. 9A). Eventualmente, ocorrem agregados de palhetas de biotita em arranjo decussado, o que caracterizaria um crescimento em condiçōes de pressão hidrostática (Vernon 1976). Nesta situação, as biotitas sobrecrescem a estruturas $\mathrm{D}_{2}$. Já as granadas formam porfiroblastos milimétricos, cujas relaçōes com a matriz apontam para um crescimento $\sin -\mathrm{D}_{2}$. Na figura 9B a granada sobrecresceu a $S_{1}$ no estágio mais inicial da crenulação por $\mathrm{D}_{2}$. A continuação da deformação levou, na matriz, à transposição quase total de $S_{1}$. Em resumo, o metamorfismo iniciado em $\mathrm{D}_{1}$ atingiu o auge quando do desenvolvimento das estruturas $\mathrm{D}_{2}$ e as temperaturas elevadas persistiram após cessar a deformação.

As dobras $\mathrm{D}_{2}$ em escala de afloramento e na escala do cinturão apresentam um forte contraste. As primeiras são freqüentemente apertadas, em especial a sul, enquanto as grandes dobras tendem a ser abertas. Este fato, segundo Miller (1982), é sugestivo de uma deformação com um forte 


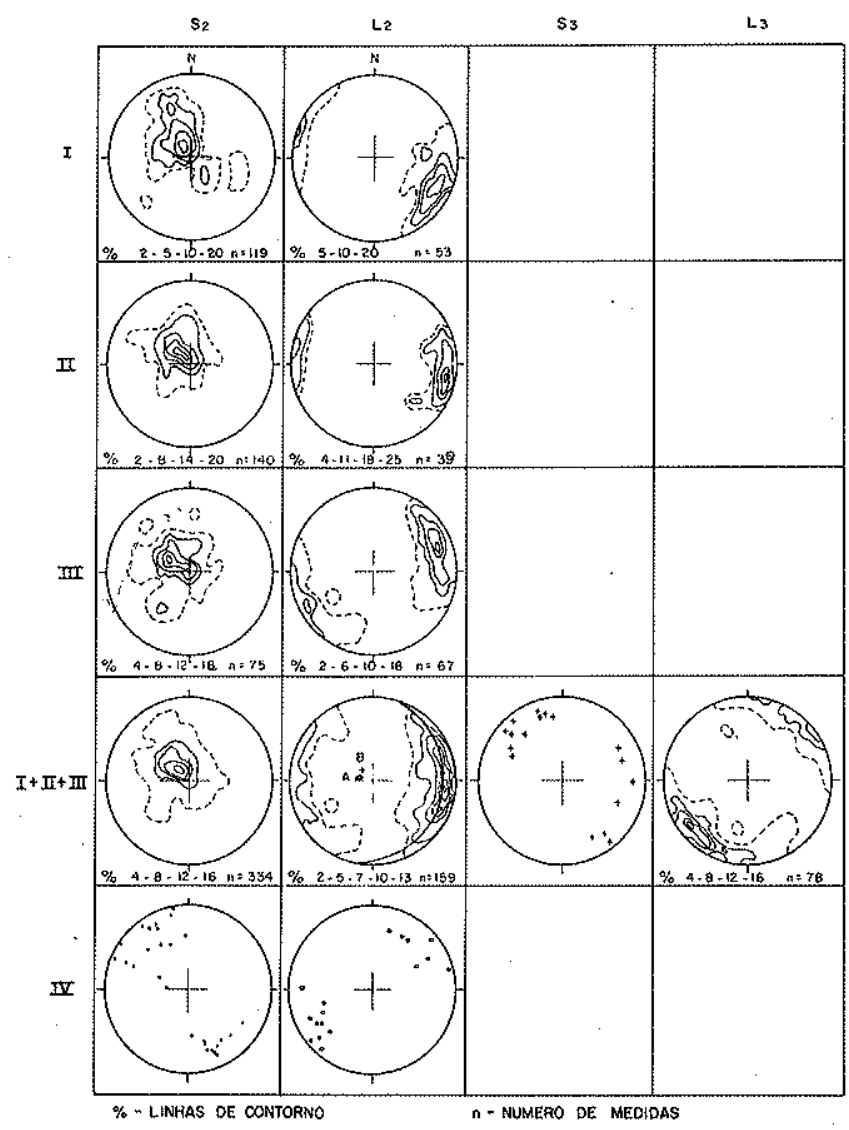

Figura 8 - Diagramas de Schmidt-Lambert relativos aos dominios I a IV. No diagrama sinoptico de $L_{2}$, a linha cheia representa o grande circulo (plano) de melhor ajuste das medidas de $L_{2}$, passando por seu máximo. A é o polo deste plano e $B$ o máximo de $S_{2}$. Nota-se a proximidade entre os dois planos

componente de cisalhamento simples sub-horizontal, paralelo a sub-paralelo aos planos de acamamento. Neste modelo, as dobras mesoscópicas sāo nucleadas a partir de perturbaçōes no fluxo causadas, por exemplo, devido a variaçöes de competência (viscosidade) ou de espessura dos estratos. Essas perturbaçōes induzem movimentos rotacionais resultando em dobramento (Lister \& Williams 1983). Essas dobras tendem a um caráter intrafolial e estilo apertado a isoclinal, muitas vezes contrastando com uma megaestrutura bem mais simples (Miller 1982). Na escala do cinturấo, o encurtamento crustal deve ter causado o arqueamento do pacote, gerando sinformais e antiformais de dimensōes quilométricas (por exemplo, o Antiformal do Lenheiro).

Os estereogramas de eixos e lineações $L_{2}$ apresentam uma distribuição em grande círculo, sugerindo um giro dentro da superficie axial $S_{2}$. Isso pode refletir uma certa reorientação dos eixos de dobra no sentido do paralelismo com o eixo $X$ de extensão máxima (Escher \& Watterson 1974, Quinquis et al. 1978, Minnigh 1979, Cobbold \& Quinquis 1980), chegando, eventualmente, a gerar dobras em bainha (Fig. 10). Na escala do cinturâo, a posiçāo dos eixos de dobra varia de E-SE a sul para E-NE a norte e nordeste (Fig. 11), ou seja, naquela regiăo mais próxima da área cratônica e que evidencia uma deformação menos intensa. E possível que a sul se tenha verificado uma rotação dos eixos devido aos valores maiores do cisalhamento, enquanto a norte estes se mantiveram próximos a posição original. Entretanto, outros fatores devem ser considerados, como a anisotropia determinada pelas

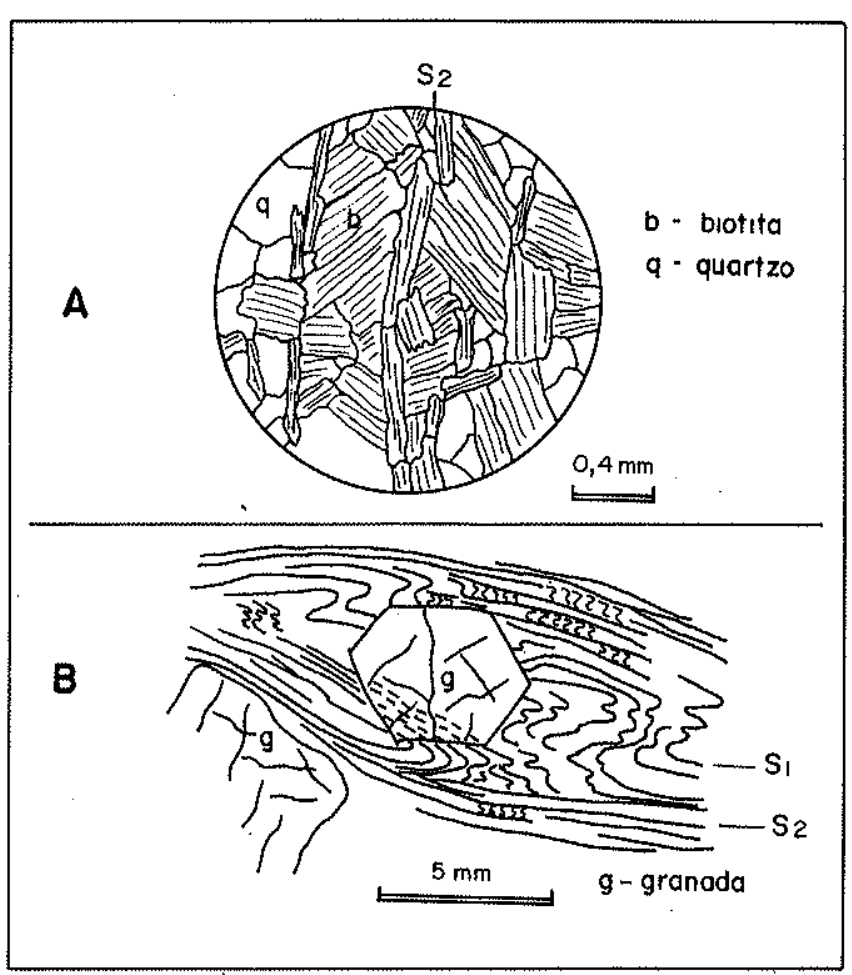

Figura 9 - Relações metamorfismo $x$ deformação: A. aspecto da clivagem de crenulação $S_{2}$, exibindo biotitas crescidas segundo a clivagem anterior, $S_{1}, e$ biotitas neoformadas orientadas segundo $S_{2}$; . porfiroblastos de granada evidenciando um crescimento $\sin -D_{2}$

espessas massas de quartzito e calcário, bem como a atuação da fase $D_{3}$.

A fase de deformação $D_{3}$ parece representar um evento deformativo distinto do anterior, de intensidade menor e em condiçōes metamórficas pouco elevadas.

$\mathrm{O}$ mecanismo da deformação $\mathrm{D}_{3}$, conforme indicam as estruturas subverticais, foi possivelmente diverso daquele proposto para $D_{1} / D_{2}$. Dayan (1983) elaborou um modelo para

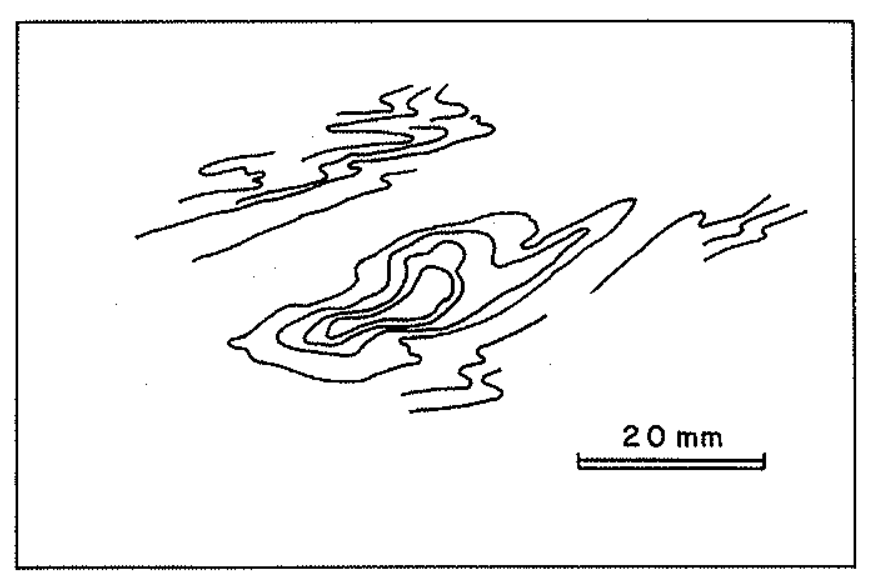

Figura 10 - Possivel dobra "em bainha" em xisto da Formação Rio Elvas. Tais dobras podem ter-se desenvolvido, esporadicamente, em zonas de deformação mais intensa, o que é compativel com a hipotese de a deformação $D_{1} / D_{2}$ incluir um importante componente de cisalhamento simples. Posiçāo aproximada do eixo da dobra a $N W-S E$ 


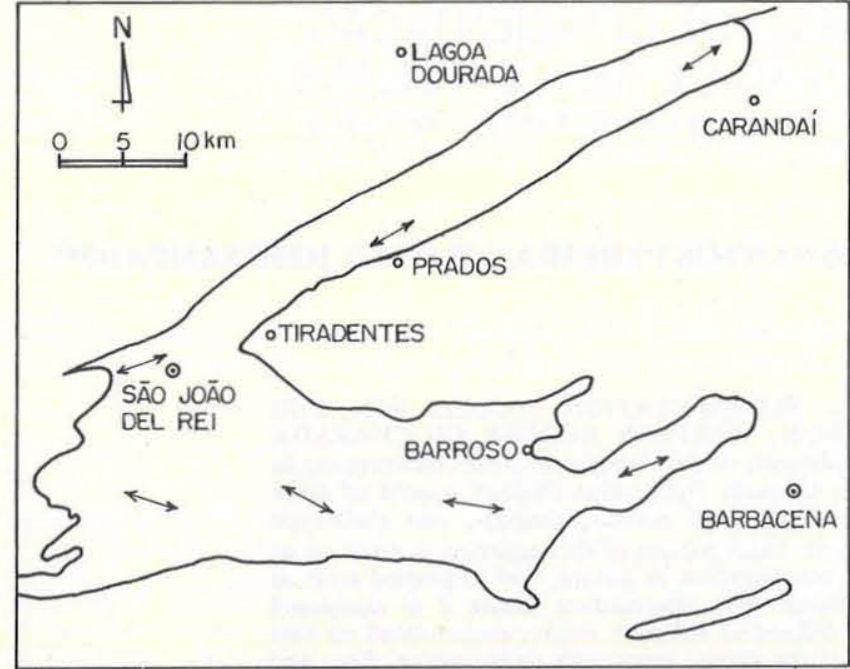

Figura 11 - Orientação média dos eixos de dobras $D_{2} e$ lineações associadas (interseção e crenulação)

a última fase na regiấo de Carrancas, onde em um estágio inicial a deformação seria absorvida pelo encurtamento do pacote (layer parallel shortening), gerando-se as crenulaçōes e dobras menores. Com a progressẫo da deformação ocorreria então o arqueamento do pacote por flambagem e/ou flexura, resultando as dobras em grande éscala. Essa seqüência da deformaçāo foi deduzida em função de minuciosa análise geométrica da orientação dos elementos estruturais, que não pode, evidentemente, ser transplantada para a região estudada. No entanto, as premissas básicas do modelo, quais sejam, encurtamento e flambagem/flexura, são aparentemente os mecanismos mais condizentes com a deformação $D_{3}$. Determinações do elipsóide de deformação para a última fase, apresentadas por Dayan \& Baptista Filho (1984), também na área de Carrancas, revelam uma deformação de baixa intensidade, com encurtamento máximo da ordem de $20 \%$. A direção de encurtamento máximo (Z) é sub-horizontal e ortogonal aos eixos de dobra (paralelos a Y). A direção de extensảo máxima é subvertical. Esses dados fornecem um modelo "clássico" para a deformação $\mathrm{D}_{3}$, com uma compressão direcionada SE-NW gerando dobramentos de eixo NE-SW. Considerando que a orientaçâo dos eixos de dobras e crenulações $D_{3}$ apresenta o máximo em 225/08 na região de São João del Rei-Barbacena, é razoável supor uma certa constância na orientação dos eixos da deformação $\mathrm{D}_{3} . \mathrm{A}$ intensidade da deformação, entretanto, foi provavelmente menor, comparando-se o melhor desenvolvimento das estruturas $\mathrm{D}_{3}$ na área de Carrancas.

Agradecimentos $\mathrm{O}$ autor expressa seu reconhecimento à orientação do Professor Dr. Rudolph A.J. Trouw. Agradecemos a Maria Cristina Teixeira, pela datilografia, e a Frederico Rosa e Silva, pelos desenhos. Os recursos financeiros foram fornecidos pelo CNPq e CNPq/UFMG.

\section{REFERÊNCIAS BIBLIOGRÁFICAS}

BELL, T.H. \& RUBENACH, M.J. 1983. Sequential porphyroblast growth and crenulation cleavage developement during progressive deformation. Tectonophysics, 92:171-194.

COBBOLD. P.R.\& QUINQUIS, H, 1980. Development of sheath folds in shear regimes. J. Struct. Geol., 2(1/2):119-126.

DAYAN, H. 1983. A estrutura de redobramento das serras de Carrancas e Bicas. IG-UFRJ. Relatório ao CNPq (inédito). $52 \mathrm{p}$.

DAYAN, H. \& BAPTISTA FILHO, J. 1984. Caracterizaçāo de fábrics tridimensionais nos rods de quartzo da base da Serra de Carrancas, SE de Minas Gerais. In: CONGR, BRAS, GEOL., 33, Rio de Janeiro, 1984, Anais... Rio de Janeiro, SBG. v. 7, p. 3371-3392.

EBERT, H. 1956. A tectônica do sul do Estado de Minas Gerais e regiōes adjacentes. In: DNPM/DGM. Relatório Anual do Diretor, ano de 1956. Rio de Janeiro, p. 97-107; 136-137.

EBERT, H. 1957. Beitrag zur des Prakambriums in Minas Gerais. Geologische Rundschau, 45(3):451-521.

EBERT, H. 1958. Discordâncias pré-cambrianas em Carandấ, Minas Gerais. Rio de Janeiro, DNPM/DGM. 48 p. (Boletim 183)

EBERT, H. 1968. Ocorrências da fácies granulítica no sul de Minas Gerais e em áreas adjacentes, em dependência da estrutura orogênica: hipóteses sobre sua origem. Rio de Janeiro, An. Acad. bras. Ciênc., 40:215-299 (suplemento).

EBERT, H. 1984. Aspectos de geologia da regiāo de Sāo Joâo del Rei. Os Paraibides entre São Joāo del Rei e Itapira e a bifuração entre Paraibides e Araxaides. São Paulo, SBG/Núcleo SP. 103 p. (Publicaçảo 12)

ESCHER, A. \& WATTERSON. 1974. Stretching fabrics, folds and crustal shortening. Tectonophysics, 22:223-231.

GRAY, D.R. \& DURNEY, D.W. 1979. Crenulation cleavage differentiation: implications of solution-deposition processes. $J$. Structural Geol, 1(1):73-80.

HOBBS, B.E.; MEANS, W.D.; WILLIAMS, P.F. 1976. An outline of structural geology. New York, John Wiley \& Sons, 571 p.

LISTER, G.S. \& WILLIAMS, P.F. 1983. The partitioning of deformation in flowing rock masses. Tectonophysics, 92:1-33.

MALTMAM, A.J. 1981. Primary bedding paralell fabrics in structural geology. J. Geol. Soc. Lond., 139:475-483.

MARSHAK, S. \& ENGELDER, T. 1985. Development of cleavage in limestones of a fold-thrust belt in eastern New York. J. Struct. Geol., 7(3/4):345-359.

MILLER, Yu. V. 1982. Stratal and substratal flow of rocks and its role in structural development. Geotectonics, 16(6):493-499.

MINNIGH, L.D. 1979. Structural analysis of sheath folds in a metachert from the western Italian Alps. J. Struct. Geol., 1(1):275-282.

NICHOLSON, R. 1966. Metamorphic differentiation in crenulated schists. Nature, 209:68-69.
NOCE, C.M. 1987a. Estudo geológico-estrutural do Grupo Säo João del Rei na regiäo de Tiradentes-Barroso-Barbacena (Minas Gerais), $e$ consideraçōes sobre seu embasamento. Rio de Janeiro, 156 p. (Dissertação de Mestrado, IG-UFRJ).

NOCE, C.M. 1987b. Uma interpretaçäo da clivagem $\mathrm{S}_{1}$ e primeira fase de deformaçāo em cinturốes dobrados de baixo grau - o caso do Grupo São Joāo del Rei. In: SIMP. GEOL. MINAS GERAIS, 4, Belo Horizonte, 1987. Anais... Belo Horizonte, SBG. p. 226-236 (Boletim 7).

QUINQUIS, H.; AUDREN, C.L.; BRUN, J.P.; COBBOLD, P.R. 1978. Intense progressive shear in Île de Groix blueschists and compatibility with subduction or obduction. Nature, 273:43-45.

RIBEIRO, A. 1983. Dados atuais do mapeamento geológico-estrutural da folha Itumirim, MG. In: SIMP. GEOL. MINAS GERAIS, 2 Belo Horizonte, 1983. Anais... Belo Horizonte, SBG. p. 461-468 (Boletim 3).

SANDERSON, D.J. 1974. Patterns of boudinage and apparent stretching lineation developed in folded rocks. J. Geol., 82:651-661.

TROUW, R.Ą.J. 1983. Novos dados sobre os grupos São João del Rei, Carrancas e Andrelândia. In: SIMP. GEOL. MINAS GERAIS, 2 Belo Horizonte, 1983. Anais... Belo Horizonte, SBG. p. 468-477 (Boletim 3).

TROUW, R.A.J.; RIBEIRO, A.; PACIULLO, F.V.P. 1983. Geologia estrutural dos grupos São João del Rei. Carrancas e Andrelândia, sul de Minas Gerais. Rio de Janeiro, An. Acad. bras. Ciênc., 55(1):71-85.

TURNER, F.J. \& WEISS, L.E. 1963. Structural analysis of metamorphic tectonites. New York, McGraw-Hill. 545 p.

VALERIANO, C.M. 1985. Geologia estrutural e estratigrafia do Grupo São João del Rei na região de São Joäo del Rei, Minas Gerais. Rio de Janeiro, 105 p. (Dissertação de Mestrado, IG-UFRJ).

VALERIANO, C.M. 1986. Geologia estrutural e estratigrafia do Grupo São João del Rei na regiäo de São João del Rei, MG. In: CONGR. BRAS. GEOL., 34, Goiânia, 1986. Anais... Goiânia, SBG. v. 2, p. 999-1018.

VERNON, R.H. 1976. Metamorphic processes - reaction and microstructure development. London, George Allen \& Unwin. 247 p.

WILLIAMS, P.F. 1972. Development of metamorphic layering and cleavage in low grade metamorphic rocks at Bermagui, Australia. Am.J.Sci., 272:1-47. 